\title{
The 1986-1989 ENSO cycle in a chemical climate model
}

\author{
S. Brönnimann ${ }^{1}$, M. Schraner ${ }^{1}$, B. Müller ${ }^{1}$, A. Fischer ${ }^{1}$, D. Brunner ${ }^{1}$, E. Rozanov ${ }^{1,2}$, and T. Egorova ${ }^{2}$ \\ ${ }^{1}$ Institute for Atmospheric and Climate Science, ETH Zurich, Universitätsstr. 16, CH-8092 Zurich, Switzerland \\ ${ }^{2}$ PMOD/WRC, Dorfstr. 33, CH-7260 Davos, Switzerland
}

Received: 1 March 2006 - Published in Atmos. Chem. Phys. Discuss.: 18 May 2006

Revised: 30 August 2006 - Accepted: 16 October 2006 - Published: 18 October 2006

\begin{abstract}
A pronounced ENSO cycle occurred from 1986 to 1989 , accompanied by distinct dynamical and chemical anomalies in the global troposphere and stratosphere. Reproducing these effects with current climate models not only provides a model test but also contributes to our still limited understanding of ENSO's effect on stratosphere-troposphere coupling. We performed several sets of ensemble simulations with a chemical climate model (SOCOL) forced with global sea surface temperatures. Results were compared with observations and with large-ensemble simulations performed with an atmospheric general circulation model (MRF9). We focus our analysis on the extratropical stratosphere and its coupling with the troposphere. In this context, the circulation over the North Atlantic sector is particularly important. Relative to the La Niña winter 1989, observations for the El Niño winter 1987 show a negative North Atlantic Oscillation index with corresponding changes in temperature and precipitation patterns, a weak polar vortex, a warm Arctic middle stratosphere, negative and positive total ozone anomalies in the tropics and at middle to high latitudes, respectively, as well as anomalous upward and poleward Eliassen-Palm (EP) flux in the midlatitude lower stratosphere. Most of the tropospheric features are well reproduced in the ensemble means in both models, though the amplitudes are underestimated. In the stratosphere, the SOCOL simulations compare well with observations with respect to zonal wind, temperature, EP flux, meridional mass streamfunction, and ozone, but magnitudes are underestimated in the middle stratosphere. With respect to the mechanisms relating ENSO to stratospheric circulation, the results suggest that both, upward and poleward components of anomalous EP flux are important for obtaining the stratospheric signal and that an increase in strength of the Brewer-Dobson circulation is part of that signal.
\end{abstract}

Correspondence to: S. Brönnimann

(broennimann@env.ethz.ch)

\section{Introduction}

On a global scale, the most important (and potentially predictable) mode of interannual climate variability is $\mathrm{El}$ Niño/Southern Oscillation (ENSO). It affects not only climate in tropical regions, but also in the extratropics and in the stratosphere. While the climatic influence in the PacificNorth American sector is well known and understood (e.g., Alexander et al., 2002), the effects in other parts of the world are less well established. Understanding these effects is important, e.g., with respect to seasonal climate forecasting. As to the stratosphere, the ENSO signal is relevant as it affects the ozone layer as well as stratospheric dynamics (Brönnimann et al., 2004).

The ENSO signal in the stratosphere is neither well known nor completely understood. Many El Niño events are accompanied by a weak and warm polar vortex both in models and observations; a signal that appears in the upper stratosphere in early January and then propagates downward and dominates the lower stratosphere in late winter (e.g., van Loon and Labitzke, 1987; Sassi et al., 2004; Manzini et al., 2006; Brönnimann et al., 2004; Garcia-Herrera et al., 2006; see also Taguchi and Hartmann, 2006). In climate models, ENSO affects stratosphere-troposphere coupling (e.g., Pyle et al., 2005) and stratospheric chemistry (e.g., Sassi et al., 2004). However, the signal is not reproduced in all model studies (see references in Manzini et al., 2006) and in observationbased studies it has been found difficult to separate the ENSO signal from other effects such as the Quasi-Biennial Oscillation (QBO) or volcanic eruptions. The effect on Arctic ozone has only rarely been addressed.

The circulation in the Arctic stratosphere is closely related to the tropospheric circulation in the North AtlanticEuropean sector (e.g., Hartmann et al., 2000; Baldwin and Dunkerton, 2001; Ambaum and Hoskins, 2002) and hence understanding the stratospheric ENSO signal requires an understanding of the ENSO climate signal in the North

Published by Copernicus GmbH on behalf of the European Geosciences Union. 
Atlantic-European area. The latter, however, is a matter of ongoing discussion. In statistical studies, several authors found a symmetric signal that resembles the North Atlantic Oscillation (NAO) and supposedly results from a downstream propagation of a wave disturbance from the PacificNorth American sector in the form of a stationary wavetrain, possibly maintained by a transient-eddy feedback (e.g., Fraedrich and Müller, 1992; Fraedrich, 1994). However, others found an asymmetric signal (e.g., Wu and Hsieh, 2004) or a signal that is strong for La Niña but weak or absent for El Niño (e.g., Pozo-Vázquez et al., 2005). This is important with respect to the interpretation of the stratospheric signal. Hence, trying to reproduce the ENSO signal in the North Atlantic-European area and the stratosphere with climate models not only serves as a model test but also promotes our understanding of ENSO mechanisms.

In this study we analyse the effects of a pronounced El Niño/La Niña cycle on the circulation of the extratropics and the northern stratosphere using ensemble simulations with a chemical climate model (CCM). Ensemble simulations provide multiple realisations of numerical predictions of the atmospheric state, which allows analysing probabilities and frequency distributions. The observed state ideally should fall within the ensemble spread. Although standard for atmospheric general circulation models (AGCMs), ensemble simulations are less common for CCMs and, to our knowledge, have not yet been systematically used for addressing ENSO effects. We compare our results with observations as well as with existing large-ensemble simulations performed with an AGCM. The latter comparison serves as a test for the robustness of the modelled tropospheric signal, which is a prerequisite for analysing the stratospheric signal.

Before models can be analysed with respect to inter-event variability or combinations of influences, they should be able to reproduce a standard ENSO cycle. For our study we therefore chose an ENSO cycle that follows the "canonical" case with respect to the observed circulation anomalies in the Pacific-North American and North-Atlantic European sectors and the stratosphere. However, the "canonical" case is primarily a statistical construct and rarely occurs in nature. With respect to the ENSO signal in the stratosphere (but also at the Earth's surface), volcanic eruptions as well as the QBO have a modulating effect. The same might be true for anthropogenic influences, most importantly ozone depletion. Nevertheless, a close to "canonical" ENSO cycle occurred 1986-1989, which comprises an average El Niño in the winter 1986/87 and a relatively pronounced La Niña in the winter 1988/89. The cycle was not coincident with volcanic eruptions, the two opposite ENSO events both occurred during easterly phases of the QBO, and greenhouse gas concentrations, aerosol loadings, and stratospheric chlorine loading were not very different for the two events. Note, however, that solar irradiance was different for the two cases, 1986/87 being close to a minimum, $1988 / 89$ close to a maximum of the sunspot cycle.
One or both events have been studied by many others using oceanographic and atmospheric data (e.g., Kousky and Leetma, 1989; McPhaden et al., 1990; Miller et al., 1988) and models (e.g., Hoerling et al., 1992; Hoerling and Ting, 1994; Sardeshmukh et al., 2000). Climate effects in Europe have also been addressed (e.g., Palmer and Anderson, 1993; Fraedrich, 1994; Sardeshmukh et al., 2000; Compo et al., 2001; Mathieu et al., 2004). The latter studies have demonstrated that atmospheric circulation over the North AtlanticEuropean sector during this ENSO cycle was in relatively good agreement with the "canonical" ENSO effects found in other studies (e.g., Fraedrich and Müller, 1992; Merkel and Latif, 2002; Brönnimann et al., 2004). Hence, this ENSO cycle provides a good opportunity to assess the ability of current models to reproduce the ENSO effects and in addition helps to better understand the observed dynamical and chemical effects in the polar stratosphere.

The paper is organised as follows. Section 2 describes the observational data sets used and the set-up of the model experiments. In Sects. 3.1 and 3.2 we analyse the results for the troposphere and for the stratosphere, respectively. Discussion and conclusions are presented in Sects. 4 and 5, respectively.

\section{Observational data and model description}

The main tool for our analysis is the CCM SOCOL (for details see Egorova et al., 2005). It combines a modified version of the AGCM MAECHAM4 (Manzini et al., 1997) and the chemistry-transport model MEZON (Rozanov et al., 1999; Egorova et al., 2003). The radiation scheme is based on the ECMWF radiation code (Fouquart and Bonnel, 1980; Morcrette, 1991). The model was run with a horizontal resolution of T30 and 39 levels (model top at $0.01 \mathrm{hPa}$ ). A 26year long (1975-2000) transient simulation (Rozanov et al., 2005) was used as climatology (termed S0, note that no detrending was performed on this simulation). The solar forcing was taken from Lean (2000). For each of the two winters an ensemble of 11 simulations was performed (S1). A second ensemble of 11 simulations per winter (S2) was later performed with an updated version of the model, which allows addressing the robustness of the results with respect to changes in the model stratosphere. These include a different aerosol forcing (SPARC stratospheric aerosol data (Thomason and Peter, 2006) instead of NASA-GISS data (Sato et al., 1993)) and a nudging of the QBO (Giorgetta, 1996). A known problem of SOCOL concerns artificial stratospheric total chlorine loss in October over the southern high-latitudes caused by the mass-fixing procedure of the applied semilagrangian transport scheme (Eyring et al., 2006). The problem mostly affects ozone hole chemistry. It is much less important for the analysis presented here because the focus is on ozone in the northern hemisphere and because we do not specifically address the effects of heterogeneous chemistry. 
Table 1. Overview of the model experiments.

\begin{tabular}{lllll}
\hline Run & SSTs & Description & Resolution/top (hPa) & No. \\
\hline M0 & Climatological Nov-Mar & MRF9 reference & T40L18/50 & 90 \\
M1 & Nov-Mar 1986/87 and 1988/89 & MRF9 ENSO & T40L18/50 & $2 \times 45$ \\
S0 & Transient (1975-2000) & SOCOL reference & T30L39/0.01 & 1 \\
S1 & Sep-Mar 1986/87 and 1988/89 & SOCOL ENSO & T30L39/0.01 & $2 \times 11$ \\
S2 & Sep-Mar 1986/87 and 1988/89 & SOCOL ENSO (modified model) & T30L39/0.01 & $2 \times 11$ \\
\hline
\end{tabular}

All simulations were started from S0 in August 1986 and 1989, respectively (in the case of S1), or in January 1986 and 1989 , respectively (S2, in order to allow another seven months of spin-up with the modified model). Initial conditions for the ensemble members were obtained by perturbing global $\mathrm{CO}_{2}$ concentration within $0.01 \%$ for one month (August 1986 and 1989, respectively). The final simulations were then performed from September to March in each winter. Meteorological variables were stored at 12-h intervals and chemical variables as monthly means ( $\mathrm{S} 1$, based on the original 2-h data) or at 12-h intervals (S2).

In the context of this paper, $\mathrm{S} 1$ and $\mathrm{S} 2$ are considered as multi-set-up experiments. Even though the ensemble means were generally very similar, there are some differences in the stratosphere that preclude us from combining the runs into one large sample.

As discussed in the introduction, our focus on stratosphere-troposphere coupling requires that the tropospheric signal is well captured. In order to test whether a standard GCM reproduces the main features of the tropospheric response in the chosen cases, we compared our simulations to existing runs performed with the AGCM MRF9. Apart from the fact that MRF9 does not include chemistry, there are also other differences to SOCOL. MRF9 was run at a higher horizontal resolution than SOCOL, but with fewer levels in the vertical.

A detailed description of the MRF9 model may be found in Kumar et al. (1996) and references therein. The simulations are described in more detail in Sardeshmukh et al. (2000) and Compo et al. (2001). The model was run at a T40 horizontal resolution with 18 sigma levels. The model top was at $50 \mathrm{hPa}$, which imposes important constraints when analysing the stratosphere. As climatology we used a set of 90 runs performed with climatological SSTs (M0). For each of the two winters, a total of 180 simulations were performed. Apart from the initial conditions, also the starting month varied. We chose sets of 45 simulations per winter that started on 1 November and were performed through March (M1). Similar ensembles starting on 1 December or 1 January gave almost the same results, but are not further described in the following. All simulations were detrended with respect to the initial fields (see Sardeshmukh et al., 2000; Compo et al., 2001). Note, however, that the trend is the same for each set and hence subtracts out when analysing El Niño-La Niña differences. Table 1 gives an overview of the model experiments.

In order to address the circulation of the troposphere and stratosphere we used ERA40 reanalysis data (Uppala et al., 2005), which are somewhat incorrectly referred to as observations in the follwing (we performed all comparisons also with NCEP/NCAR reanalysis data (Kistler et al., 2001), but refer to these comparisons only occasionally). For precipitation we used the Global Precipitation Climatology Project (GPCP) Version 2 data (Adler et al., 2003). The signal in stratospheric ozone was analysed in TOMS Version 8 total ozone data (Nimbus-7) and SAGE II (Version 6.2) ozone profiles. In addition, we also used the CATO assimilated ozone data (Brunner et al., 2006) on an equivalent latitude coordinate system, which allows focussing on changes in the diabatic mean circulation and chemical effects. The overlapping period of all data sets, i.e., 1979-2002 (no detrending was performed), was used as a reference period.

Results from the two models and observations are compared mostly with respect to late-winter (January to March) averages, when a consistent signal is expected over the North Atlantic and in the lower stratosphere (e.g., Gouirand and Moron, 2003; van Loon and Labitzke, 1987; Sassi et al., 2004; Manzini et al., 2006). Note that the expected signal is different, in fact opposite in many respects, in November and December (e.g., Mariotti et al., 2002; Moron and Plaut, 2003; Manzini et al., 2006). In order to correctly interpret the stratospheric signal, it is important that the tropospheric signal is reproduced correctly. Hence, we first analysed $1000 \mathrm{hPa}$ temperature and geopotential height (GPH) as well as precipitation. In order to address the stratospheric signal we analysed temperature, zonal wind, GPH, ozone, the components and divergence of the Eliassen Palm (EP) flux as well as the meridional mass streamfunction based on Transformed Eulerian Mean residual winds (Andrews et al., 1987).

\section{Results}

\subsection{The troposphere}

Figure 1 displays observed anomalies of temperature and $\mathrm{GPH}$ at $1000 \mathrm{hPa}$ as well as precipitation for January to 

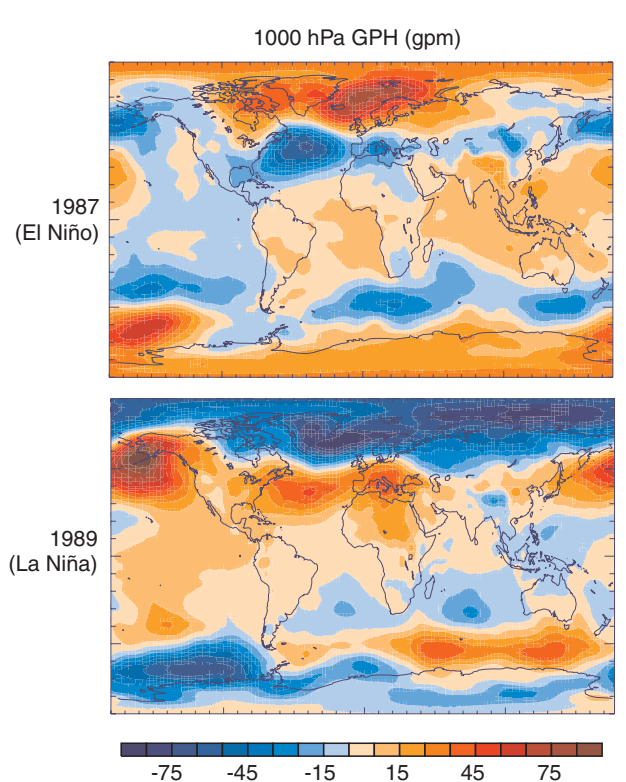
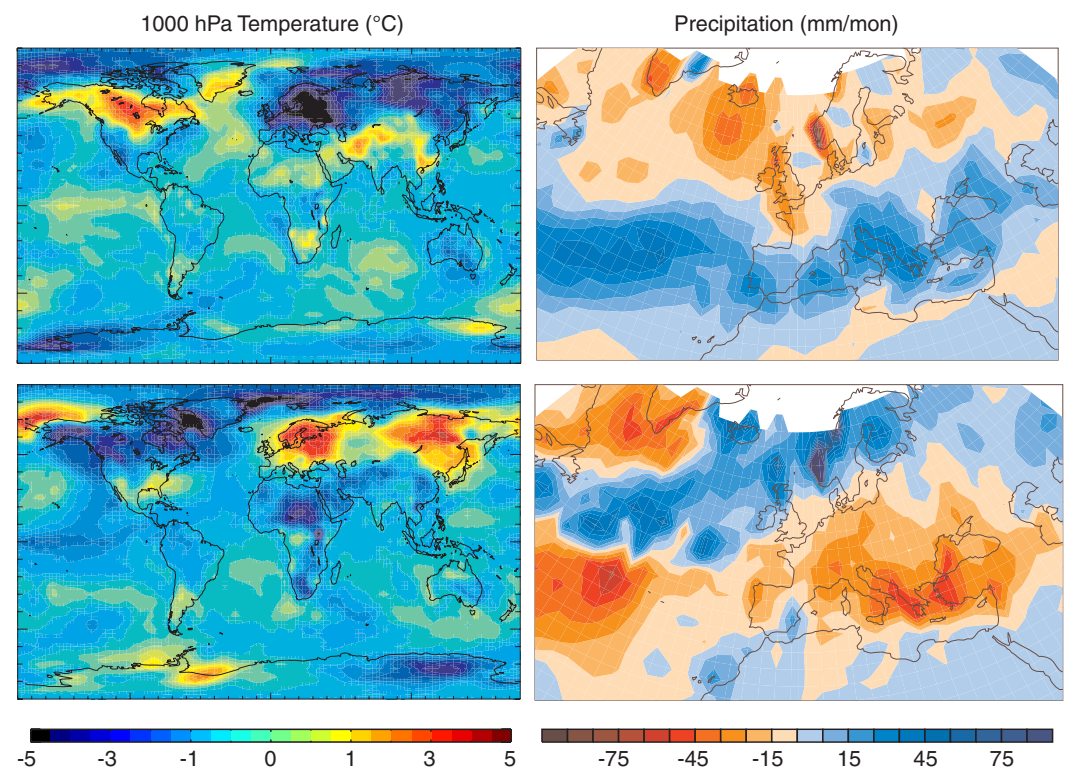

Fig. 1. Observed anomalies of $1000 \mathrm{hPa}$ geopotential height (left) and air temperature (middle) as well as precipitation (right) for January to March 1987 (top) and January to March 1989 (bottom) with respect to the 1979-2002 period.

March 1987 and 1989. The two winters exhibit the well known ENSO imprint in the North Pacific area such as a strong (weak) Aleutian low for El Niño (La Niña), accompanied by high (low) temperatures in Alaska. Temperature anomalies in northeastern Europe were strongly negative for the El Niño winter and positive for the La Niña winter. The $1000 \mathrm{hPa}$ GPH field shows a pronounced negative (positive) NAO pattern in the two winters. This is in excellent agreement with the "canonical" effect of ENSO on Europe in late winter. The El Niño winter also resembles the strong 19401942 case (Brönnimann et al., 2004). A strong precipitation signal is found especially for the La Niña winter, with negative anomalies throughout the Mediterranean area and positive anomalies in northwestern Europe. The El Niño case shows anomalies of opposite sign, but slightly weaker in amplitude. In general, the results show a close to symmetric response for these two winters with respect to most of the features, and they again suggest that 1986-1989 was a "classical" ENSO cycle with respect to its effect on the circulation over the North Atlantic-European sector.

Comparisons between simulations and observations for the two individual winters are not possible in a strict sense (and therefore not shown here) because of the different climatologies used. Nevertheless, it is interesting to note that similar to the observations, both models show a response that is close to symmetric around the respective climatology in the two winters. Model results (ensemble means) are compared to the observations in Fig. 2 in the form of the difference between the El Niño winter (1987) and the La Niña winter (1989). The amplitudes of the anomalies are generally smaller in the ensemble means than in the observations, which is expected due to averaging. The patterns, however, are relatively well reproduced by both models. For El Niño minus La Niña, all experiments show cold winters in northeastern Europe, stretching all across northern Eurasia, and a dipole pattern in $1000 \mathrm{hPa}$ GPH resembling the negative mode of the NAO (see Compo et al., 2001, for a discussion of related changes in subseasonal variability). In the SOCOL experiments as well as in the observations (but not in M1) the anomaly centres lie close to Iceland and the Azores.

For precipitation (Fig. 2), all experiments reproduce the observed decrease in Norway and the increase in the Mediterranean area. The precipitation signal over the Atlantic reflects a southward shift in the Atlantic storm track for El Niño relative to La Niña, which was also shown by Compo and Sardeshmukh (2004). As for the other fields, the magnitudes of the precipitation anomalies is underestimated. Nevertheless, in all three fields (temperature, GPH, and precipitation) the main differences between El Niño and La Niña found in the observations are also statistically significant $(t-$ test, $p<0.05$ ) in the model experiments.

Several features, on the other hand, are not well reproduced in the SOCOL model. This concerns in particular surface air temperature over the sea ice north of Alaska (also in MRF9). Also, the warming signal for El Niño minus La Niña stretching from Sudan to the Middle East is not well reproduced (again by both models).

In addition to the significance of the ensemble mean differences, it is advisable also to look at the distribution functions (see also Melo-Goncalvez et al., 2005). Figure 3 shows histograms of temperatures at a grid point near Dalarna, Swe$\operatorname{den}\left(60^{\circ} \mathrm{N} / 15^{\circ} \mathrm{E}\right)$, which is close to the location of the max- 

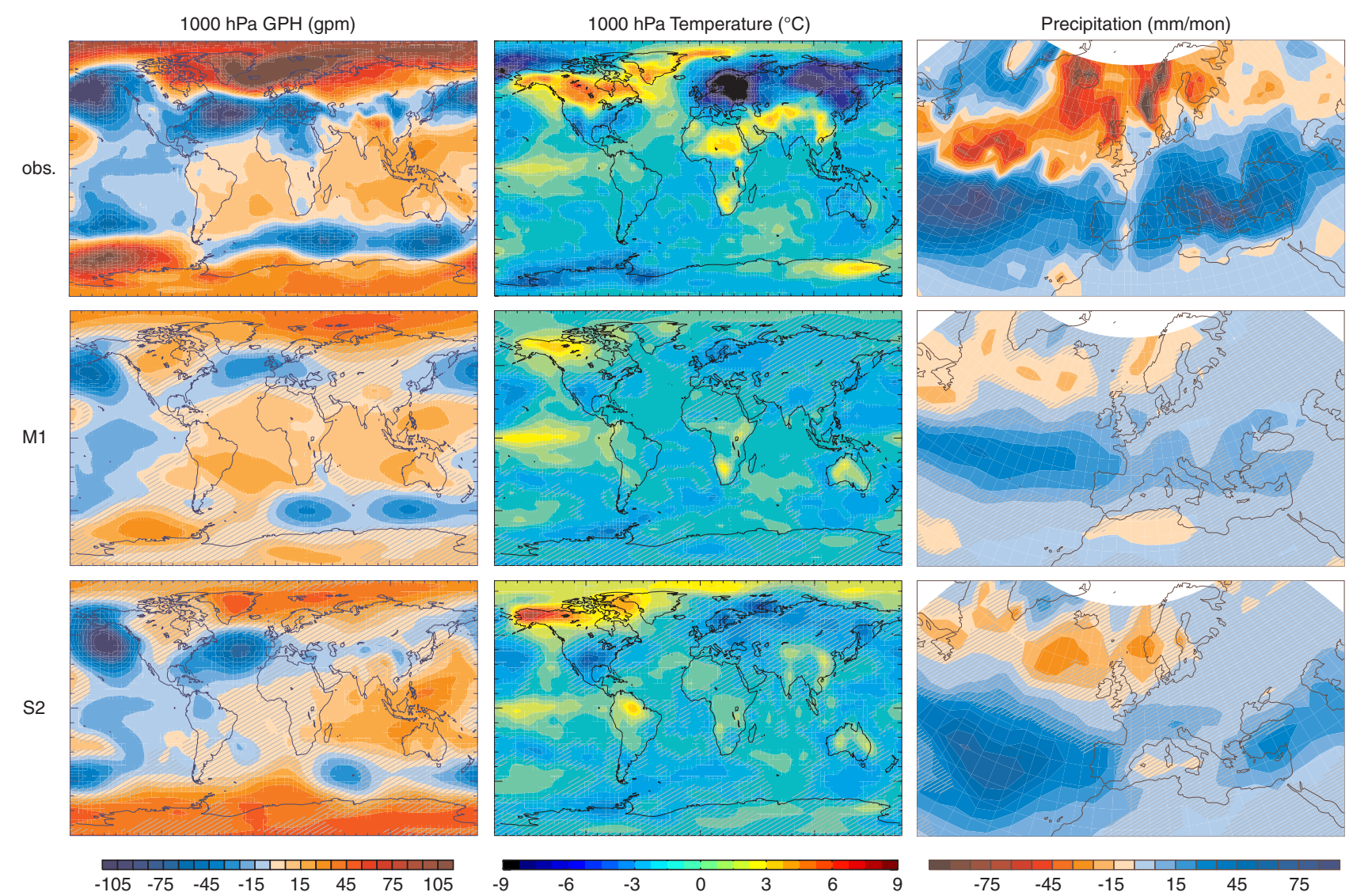

Fig. 2. Difference between January to March 1987 (El Niño) and January to March 1989 (La Niña) in 1000 hPa geopotential height (left) and air temperature (middle) as well as precipitation in the observations (top), M1 ensemble mean (middle), and S2 ensemble mean (bottom). Hatched areas are not significantly different from zero $(t$-test, $p<0.05)$.

imum $1000 \mathrm{hPa}$ temperature difference in the observations. Note, however, that the grid point is close to the Baltic Sea, where SSTs were prescribed. We therefore include a second location near Moscow, Russia $\left(55.8^{\circ} \mathrm{N}, 37.6^{\circ} \mathrm{E}\right)$. In order to obtain a larger sample we merged S1 and S2, which show a similar mean response, into one figure (but with different hatchings). First of all, it becomes obvious that the models differ both with respect to absolute values as well as variability. The surface temperature is lower in SOCOL compared to MRF9. On the other hand, the variability is higher in SOCOL than in MRF9. The low variability in M1 for the grid point near Dalarna is most likely due to the proximity of the ocean, but also for Moscow the variability is smaller in M1 than in $\mathrm{S} 1 / \mathrm{S} 2$. The observed temperatures are indicated as coloured lines. Here we use both ERA40 and NCEP/NCAR reanalysis data. They are outside the ensemble spread in many of the comparisons. While the models reproduce the sign of the difference between the two winters, they clearly underestimate the magnitude. However, it should be noted that the two observation-based data sets (i.e., two depictions of the same "realisation") also show quite substantial differences (up tp $2.5^{\circ} \mathrm{C}$ ) and that the observed magnitude amounts to $10^{\circ} \mathrm{C}$.
This is extreme for a 3-month average. In fact, long temperature records from nearby stations (not shown) indicate that the two winters were both close to the record minima and maxima, respectively.

With respect to the interpretation of ensemble means, it is clear that the modelled temperature signal shown in Fig. 2 does not arise from a few outliers, nor does it mask a bimodal behaviour.

\subsection{Stratospheric dynamics and chemistry}

In the following, we focus on the stratospheric dynamics and chemistry. Figure 4 shows difference fields for GPH and temperature at $100 \mathrm{hPa}$. For the El Niño case, temperatures were lower and GPH higher above the eastern tropical Pacific than for the La Niña case (see also Claud et al., 1999). At midlatitudes, a clear wave structure is visible in the $100 \mathrm{hPa}$ GPH field, with its main anomaly centres in the North Pacific and central Europe. Temperatures were high over northern Eurasia, but low over the North Atlantic, similar as in the case of the 1940-1942 El Niño (Brönnimann et al., 2004). The main feature at high latitudes is a weak and meridionally 

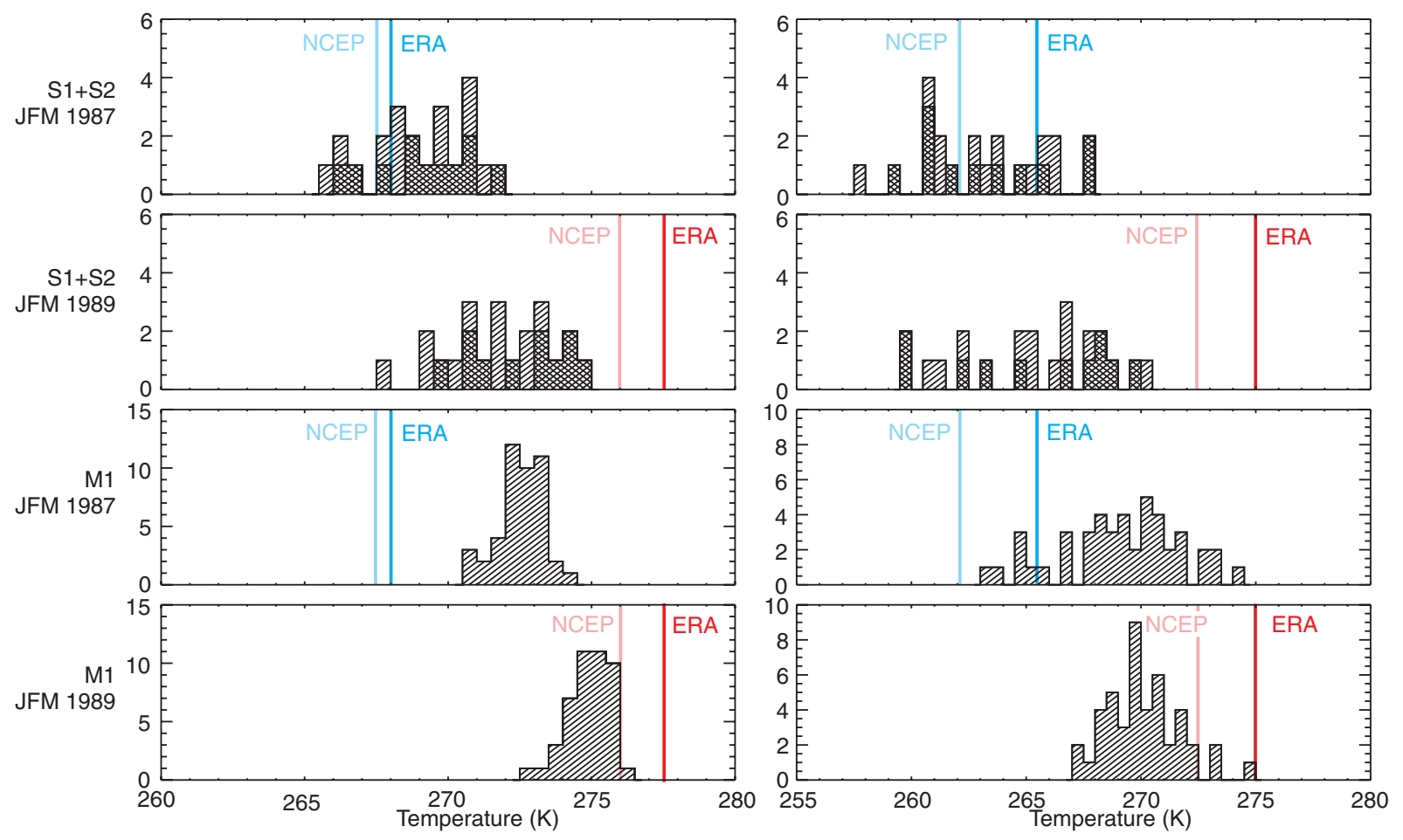

Fig. 3. Histograms of $1000 \mathrm{hPa}$ temperature near Dalarna (Sweden, left) and Moscow (Russia, right), averaged from January to March, for S1 and S2 (cross hatched) and M1 for 1987 (El Niño) and 1989 (La Niña). The blue and red lines give the corresponding values from ERA40 and NCEP/NCAR reanalysis.

expanded polar vortex, which is consistent with statistical analyses (van Loon and Labitzke, 1987) and model studies (Sassi et al., 2004; Manzini et al., 2006) and again similar to the 1940-1942 case (Brönnimann et al., 2004). In line with a weak polar vortex and again in agreement with the above mentioned studies, ERA40 temperatures were much higher in 1987 compared to 1989 over much of the Arctic. This is in part due to a major warming in January 1987.

The models reproduce the patterns in tropical temperature and GPH anomalies fairly well. MRF9 underestimates the magnitudes in both fields, whereas SOCOL slightly overestimates the GPH response. Both models also show a similar wave-structure as the observations in temperature and GPH over the North American-Pacific sector. Further downstream, over the North Atlantic, the wave-pattern is shifted westward in the models compared with the observations. The cooling over the North Atlantic is pronounced and significant in M1 and S2. In the high Arctic, however, the observed temperature signal is not well reproduced in the ensemble means. No significant effect is found except over eastern Siberia. The weak polar vortex at $100 \mathrm{hPa} \mathrm{GPH}$ is better reproduced, with a statistically significant signal in all ensemble sets. However, the magnitude is again smaller than in the observations, especially in M1. The fact that even MRF9 with a low model top shows a significantly weaker polar vortex confirms that this is a very robust part of the stratospheric ENSO signal.
In the following we focus more closely on stratospheric dynamics. This was done only for the SOCOL model, but not for MRF9, which due to its low model top is not expected to realistically reproduce processes related to wave-mean flow interaction in the middle stratosphere. In order to assess whether the propagation of quasy-steady wave-like structures into the stratosphere is correctly reproduced, we analysed the longitudinal variation of $\mathrm{GPH}$ at $50^{\circ} \mathrm{N}$ at 100 and $30 \mathrm{hPa}$ for each individual run and compared it to ERA40 data. The observations show clear differences between the two cases, with a wave number one pattern dominating in the El Niño case and a wave number two pattern in the La Niña case, most pronounced at $30 \mathrm{hPa}$. In the model, GPH is underestimated at $100 \mathrm{hPa}$ but overestimated at $30 \mathrm{hPa}$. The former could be due to a somewhat too large polar vortex whereas the latter could be affected by the vertical interpolation (the nearest model levels are $25.12 \mathrm{hPa}$ and $39.81 \mathrm{hPa}$ ). The wave structure during the El Niño case is very well reproduced by $\mathrm{S} 1$ and $\mathrm{S} 2$ both in terms of amplitude and position, particularly at $100 \mathrm{hPa}$. A clear dominance of wave number one is found. Discrepancies arise, however, for the La Niña case. At $100 \mathrm{hPa}$, a pronounced feature in the observations is the absence of the trough over western Russia. Both S1 and S2 reproduce a trough in the majority of the runs, though weaker (more so in S1 than S2) than for the El Niño case. In addition, the wave over the Atlantic-European sector is shifted west- 

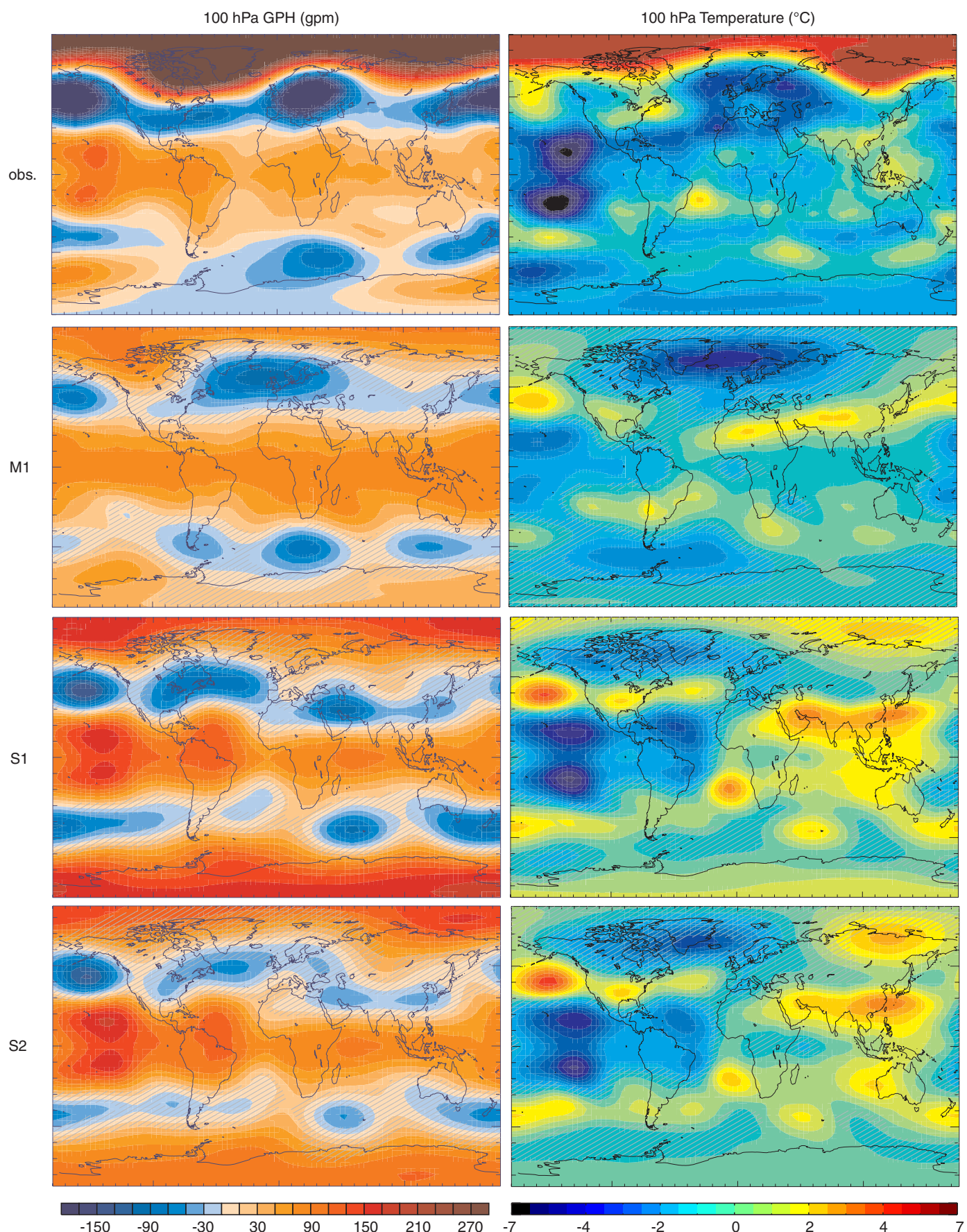

Fig. 4. Difference between 1987 and 1989 in GPH (left) and temperature (right) at $100 \mathrm{hPa}$, averaged from January to March, in ERA40, $\mathrm{M} 1, \mathrm{~S} 1$, and S2. Hatched areas are not significantly different from zero $(t$-test, $p<0.05)$.

ward in the model and the observed westward shift of the ridge over the Rocky Mountains is not similarly reproduced. In contrast to the observations, wave number one is dominating (but in agreement with observations, wave number four is strongly reduced compared to the El Niño case). At the $30 \mathrm{hPa}$ level, both S1 and S2 fail to reproduce the planetary wave structure during La Niña and the difference between El Niña and La Niña vanishes.
Figures 6 and 7 show zonal mean zonal wind and temperature as a function of latitude and altitude. In addition to the differences between 1987 and 1989, their mean value is also shown for $\mathrm{S} 1$ for the comparison of absolute values ( $\mathrm{S} 1$ and S2 are almost identical with respect to the mean value). SOCOL reproduces the structure as well as the magnitude of the zonal wind fairly well at all levels from the surface up to the middle stratosphere. The structure of the zonal 

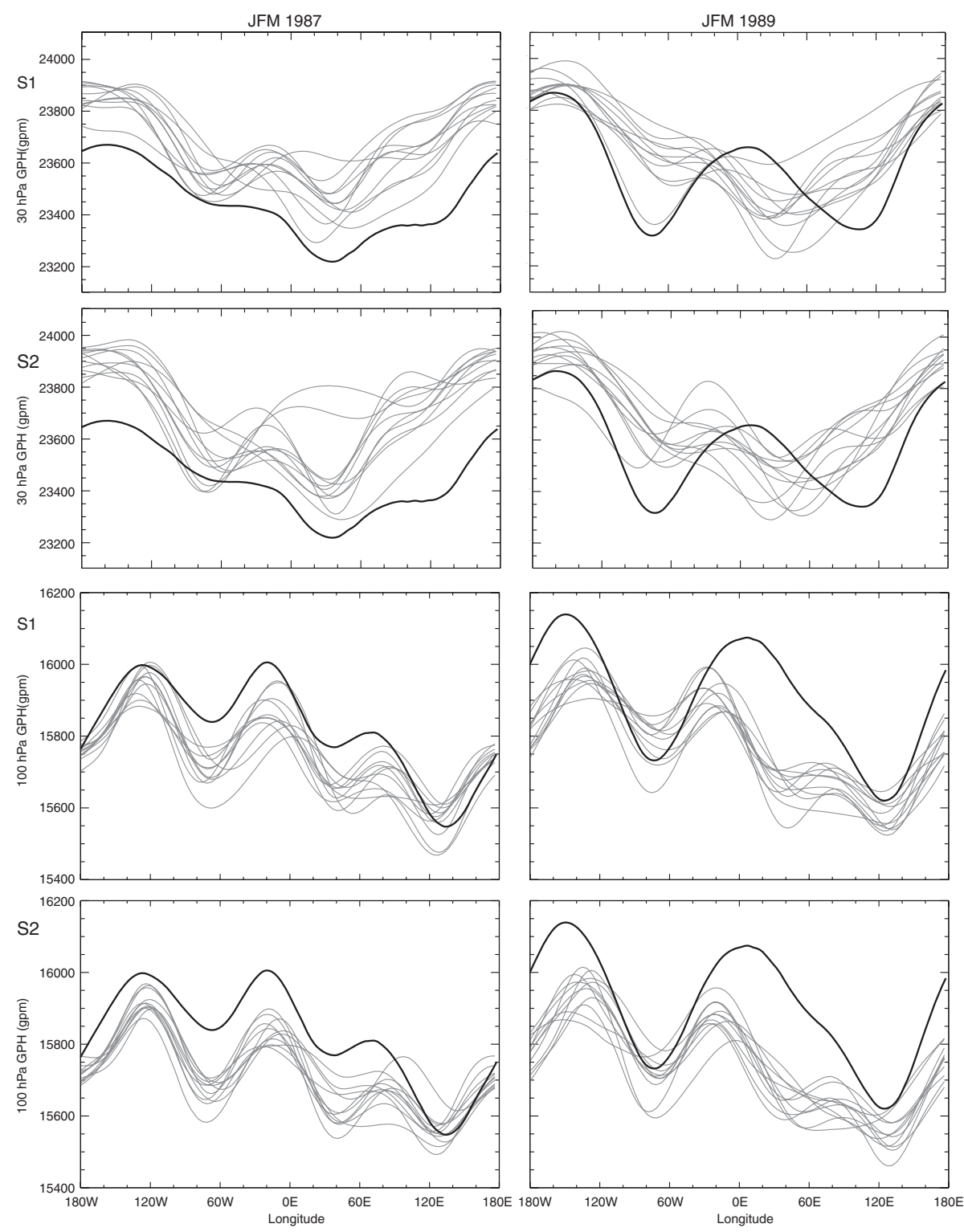

Fig. 5. Longitudinal variation of $30 \mathrm{hPa}$ and $100 \mathrm{hPa}$ GPH at $50^{\circ} \mathrm{N}$ in $\mathrm{S} 1$ and $\mathrm{S} 2$ averaged from January to March 1987 (left) and 1989 (right). The thick lines indicate ERA40 data.

mean temperature (Fig. 7) is also well reproduced, but absolute values are too low in the tropopause region and in the polar vortex. The differences between El Niño and La Niña agree well with the observations in a qualitative sense. In the zonal winds (Fig. 6) both simulations (S1 and S2) show a stronger subtropical jet and a weakened polar vortex (more so in S1 than S2), which is very similar to the ENSO signal found in statistical analyses of reanalysis data (e.g., Chen et al., 2003). Note that the subtropical jet is displaced southward in the models during El Niño compared with La Niña, but not in the observations. The magnitudes of the anomalies also agree well in the troposphere, but in the stratosphere they are clearly too small in both simulations, especially in the middle stratosphere. Significance is limited to the lowermost stratosphere and troposphere. Note that the tropical stratosphere is affected by the QBO nudging in S2. Clearly, easterly wind anomalies at the equator are stronger (more similar as in the observations) in S2 compared to S1. No obvious effects of the QBO nudging are seen in the subtropical jet and the polar vortex.

Another factor that needs to be considered is solar irradiance, which was higher in 1989 than in 1987. According to observation-based studies (Labitzke et al., 2006) one would expect a stronger northern vortex in 1989 because both events occurred during the easterly QBO phase (however, the effect for the easterly QBO phase is smaller and less cer- 

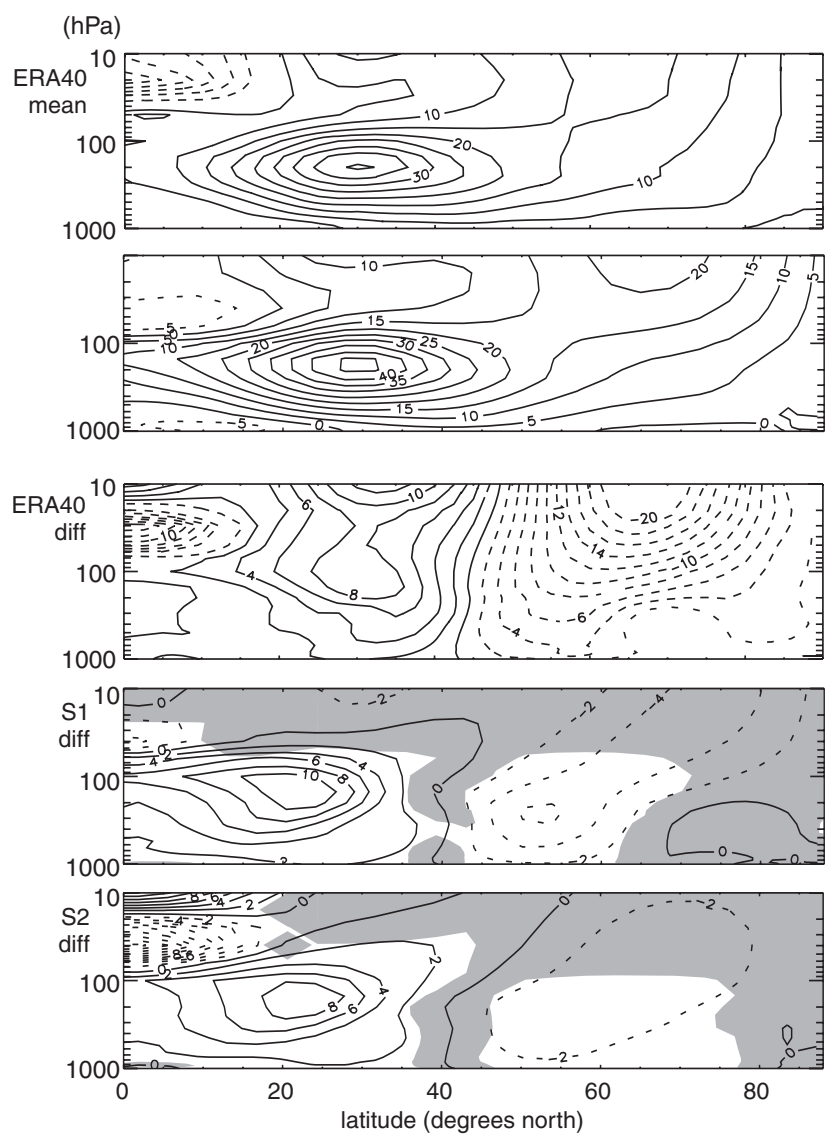

Fig. 6. Mean value and difference between 1987 and 1989 in zonal mean zonal wind $(\mathrm{m} / \mathrm{s})$, averaged from January to March, in ERA40, S1, and S2. Shaded areas are not significantly different from zero $(t$-test, $p<0.05)$.

tain than for the westerly phase). Steady-state SOCOL simulations without QBO (and hence stratospheric easterlies) found a stronger northern stratospheric polar vortex for solar maximum conditions compared to solar minimum conditions (Egorova et al., 2004), but the signal is not statistically significant and clearly smaller (around $1 \mathrm{~m} / \mathrm{s}$ ) than that in our simulations. Hence, solar irradiance changes do not seem to be sufficient to explain the signal.

Zonal mean temperature differences between El Niño and La Niña are shown in Fig. 7. The observations show a pronounced signal in the Arctic lower stratosphere. In S1, the pattern is well reproduced, but not its strength, whereas in S2 the pattern is less well reproduced. The Arctic temperature response in the model is significant below $200 \mathrm{hPa}$. At higher levels, within-ensemble variability is too large for obtaining significant results. Both S1 and S2 show a significant warming of the subtropical tropopause and lower stratosphere which is not seen in the observations. This is probably related to the southward displacement of the subtropical jet in the model (Fig. 6) that is not seen in the observations.
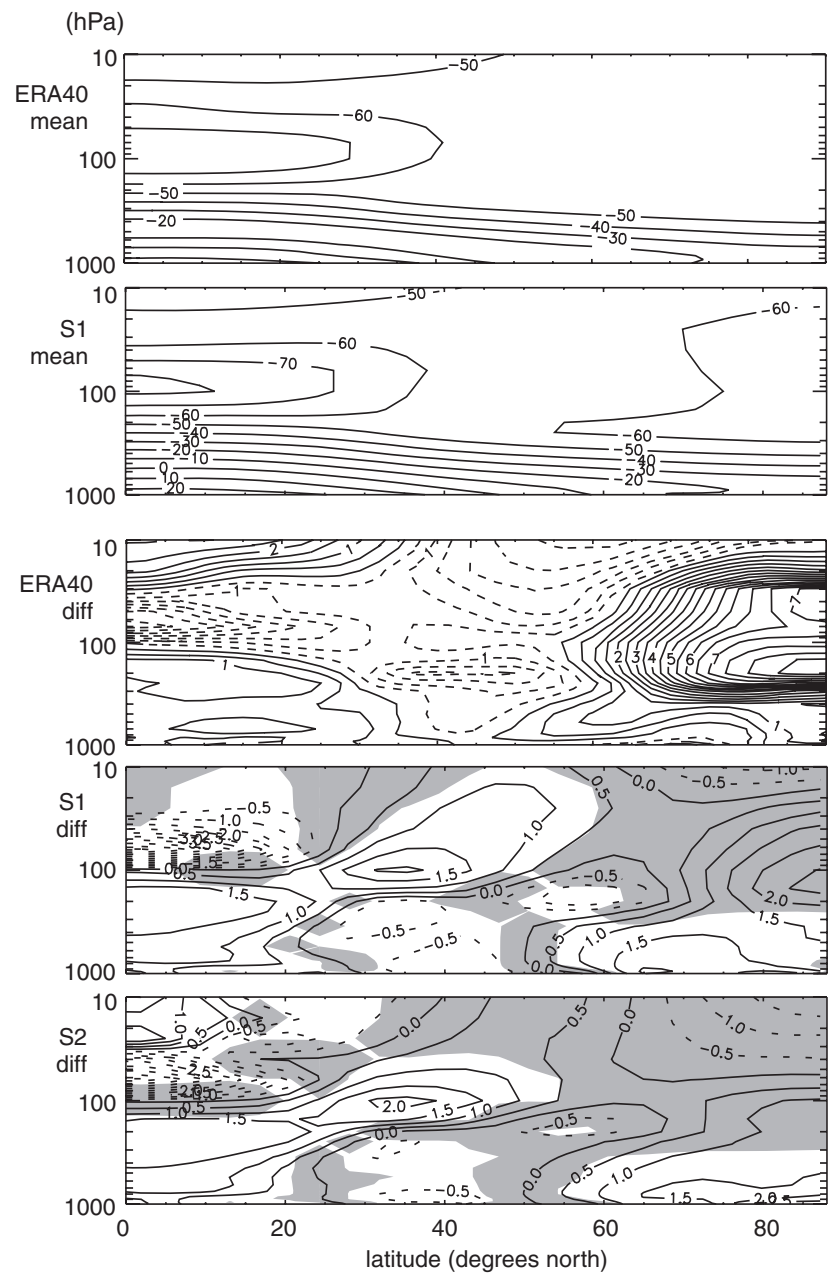

Fig. 7. Mean value and difference between 1987 and 1989 in zonal mean temperature $\left({ }^{\circ} \mathrm{C}\right)$, averaged from January to March, in ERA40, S1, and S2. Shaded areas are not significantly different from zero ( $t$-test, $p<0.05)$.

In order to understand the modelled Arctic temperature response in the stratosphere, we analysed 12-hourly series of temperature at the North Pole $\left(3.8^{\circ} \mathrm{E}, 87.2^{\circ} \mathrm{N}\right.$ in SOCOL $)$ at $10 \mathrm{hPa}$ and $100 \mathrm{hPa}$ in the individual ensemble members as well as in ERA40 (Fig. 8). The reanalysis data for 1986/87 show a strong disturbance (major midwinter warming) in January. While at $10 \mathrm{hPa}$, temperatures dropped again during February and reached very low values in March, the disturbance at $100 \mathrm{hPa}$ persisted into spring. In 1988/89, in contrast, the polar stratosphere was undisturbed and cold well into February, but the final warming then was very pronounced. In the SOCOL experiments major warmings appear in most of the simulations in both winters, sometimes already in late November or December. The large day-to-day variability causes a large within-ensemble variability, which hampers the statistical analysis of ensemble means. 

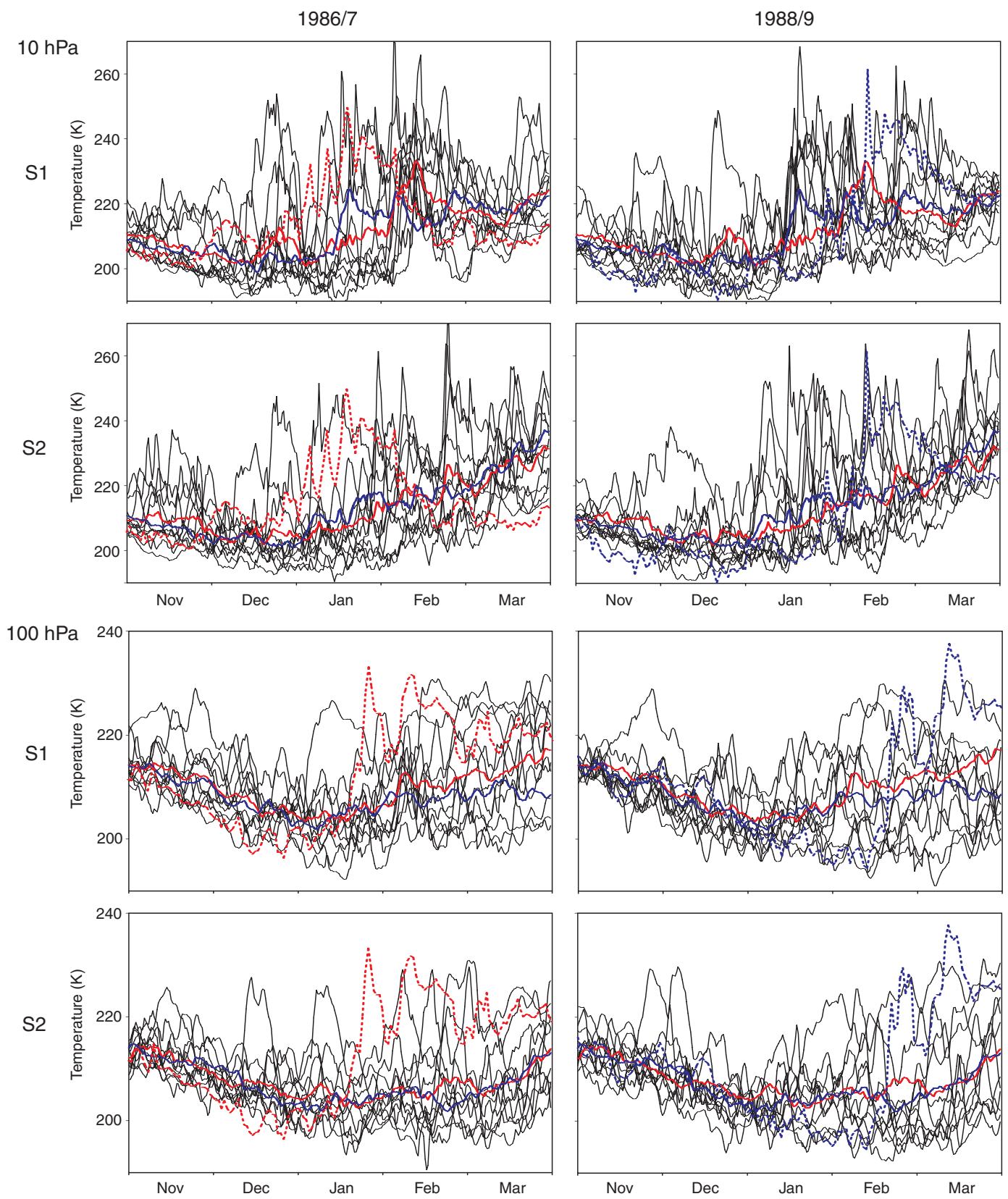

Fig. 8. 12-hourly temperature at $10 \mathrm{hPa}$ (top four panels) and $100 \mathrm{hPa}$ (bottom four panels) at the North Pole from November to March in 1986/87 (left) and 1988/89 (right) for S1 and S2. The dotted lines indicate ERA40 data, the coloured lines give the ensemble means (red: 1986/87, blue: 1988/89).

In addition to zonal wind and temperature we also analysed the EP flux as a measure of the planetary-wave driving of the stratospheric circulation. Figure 9 shows zonal means of the upward and meridional components of the EP flux as well as its divergence, again for the mean of the two winters and their difference (note that we have averaged EP flux from November to February, thus allowing a four-to-eight week lead with respect to the temperature, zonal wind, and ozone). For the mean values, the EP flux shows an excel- lent agreement with observations with respect to vertical and latitudinal structure as well as absolute values. This does not only hold for the divergence of the EP flux, but also for its vertical and meridional components. With respect to the differences between El Niño and La Niña, the observations show a negative anomaly in EP flux divergence in most of the extratropical stratosphere, which is also found in both sets of simulations. An analysis of the EP flux components implies two contributions: an increase in the vertical com- 

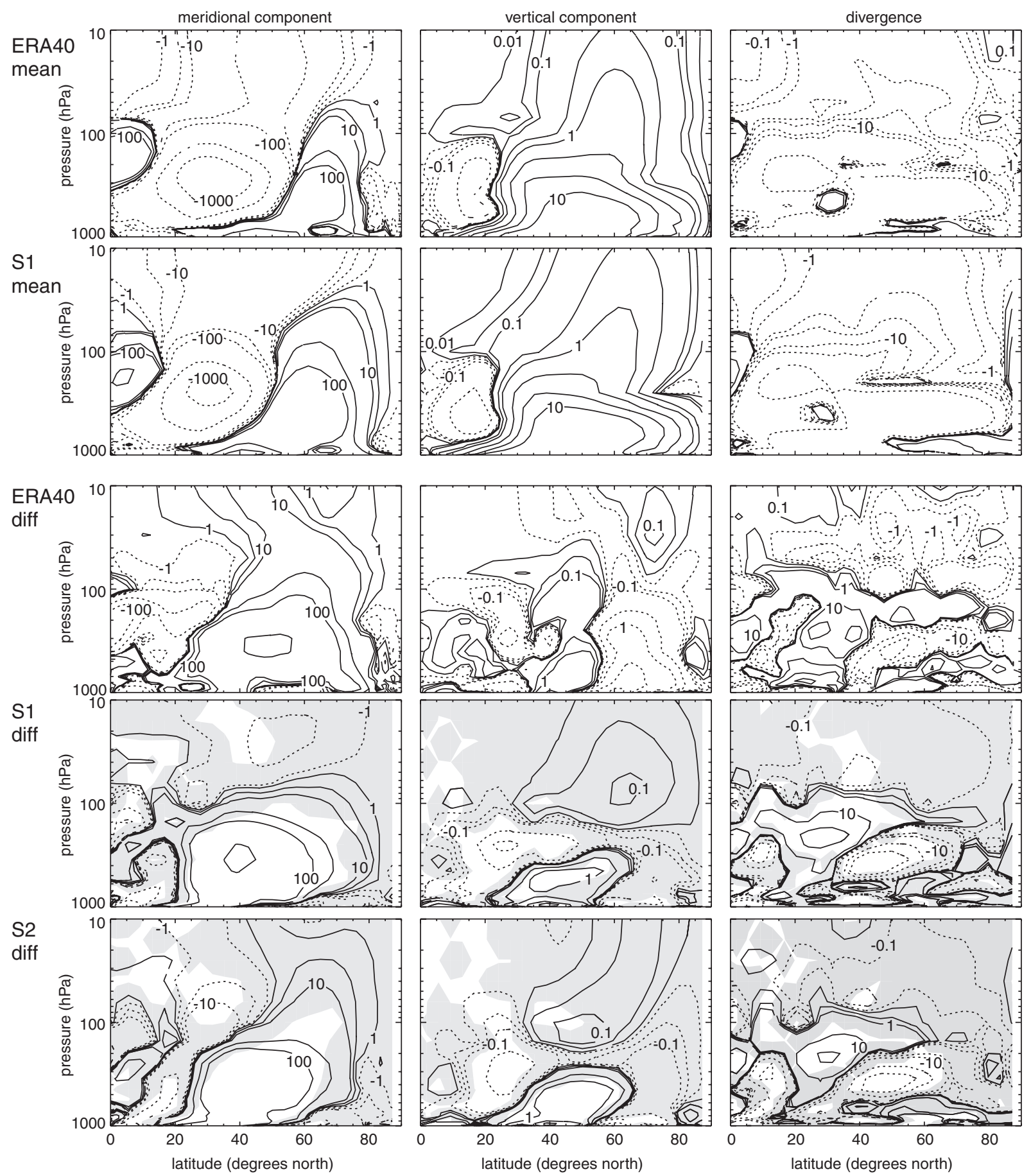

Fig. 9. Mean value and difference between El Niño and La Niña in zonal mean EP flux, averaged from November to February, in ERA40 reanalysis, S1, and S2. Left: poleward component, middle: upward component (both given as $10^{5} \mathrm{~kg} \mathrm{~s}^{-2}$ ). Right: divergence (kg $\mathrm{m}^{-1} \mathrm{~s}^{-2}$ ). Shaded areas are not significantly different from zero $(t$-test, $p<0.05)$.

ponent as well as an increase (in the lower stratosphere) of the poleward component of the EP flux. The El Niño minus La Niña differences in the meridional component are again well reproduced by both sets of simulations (except for S1 in the upper stratosphere), while the agreement is worse for the vertical component. In all cases, however, significance is limited to the troposphere and lowermost stratosphere.

In order to directly address the stratospheric meridional circulation, we calculated the meridional mass streamfunctions based on the Transformed Eulerian Mean residual ve- 

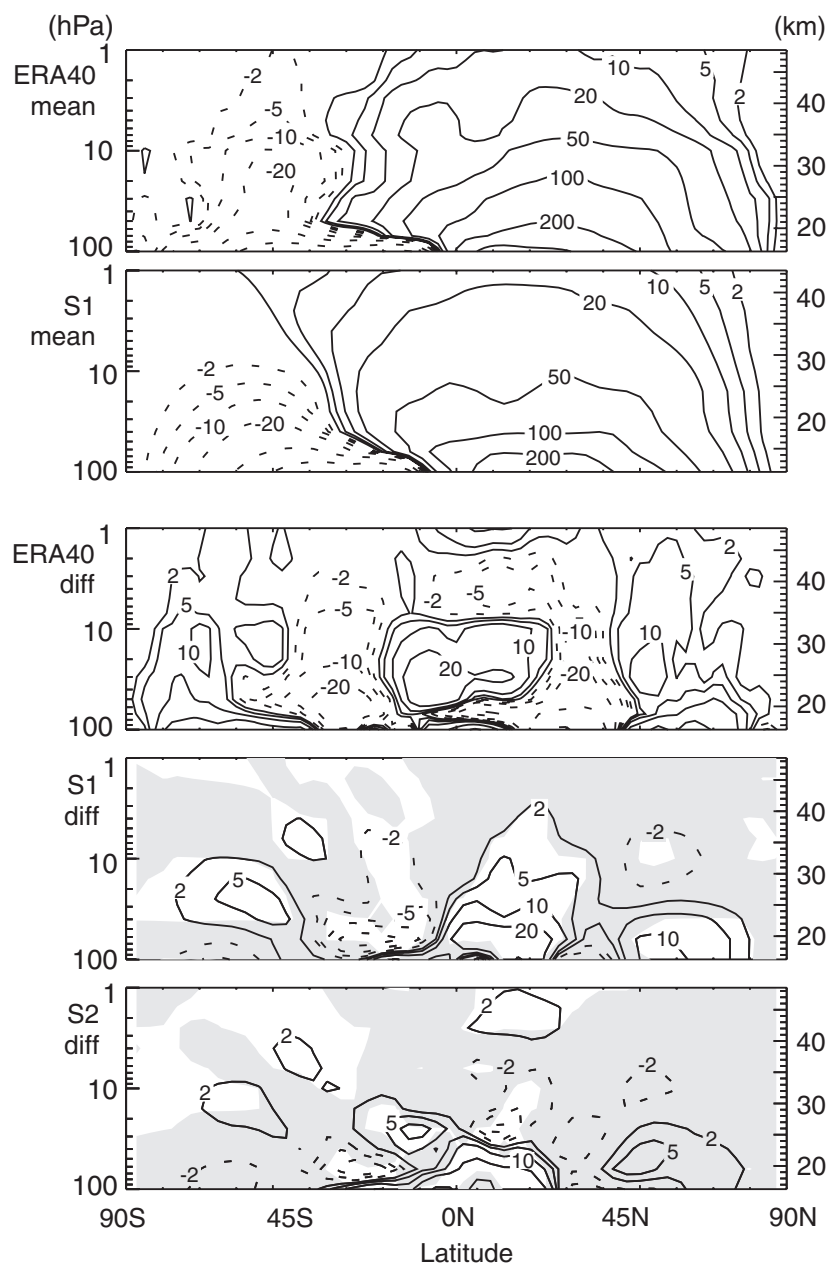

Fig. 10. Difference between El Niño and La Niña in the meridional mass streamfunction $\left(\mathrm{kg} \mathrm{s}^{-1} \mathrm{~m}^{-1}\right.$, based on the Transformed Eulerian Mean residual velocities) averaged from November to February, in ERA40 reanalysis, S1, and S2. Shaded areas are not significantly different from zero ( $t$-test, $p<0.05)$.

locities (see e.g., Butchart and Austin, 1998). The mean values and differences between El Niño and La Niña are shown in Fig. 10. The meridional mass streamfunction is very well reproduced in SOCOL on average both in terms of position and strength. The only difference is that in SOCOL, the circulation cell reaches further southward in the middle and upper stratosphere. The differences in ERA40 show generally an enhancement and northward shift of the circulation. In the lower-to-middle stratosphere, this pattern is well reproduced by SOCOL, particularly in the S1 ensemble. Even though $\mathrm{S} 2$ also shows some signs of a strengthening circulation, the signal is only significant in the tropics. The signal in the middle-to-upper stratosphere is not reproduced (and is mostly insignificant in both S1 and S2).

Further comparisons were performed with respect to ozone. Except for the subtropical middle stratosphere, ozone concentrations are higher in S1 than in S2 (not shown) be- cause of the differences in the model set-up. No such difference, however, is apparent when analysing El Niño minus La Niña. For both S1 and S2 the simulated total ozone difference (January-to-March average, Fig. 11) shows a very good agreement with TOMS observations with respect to the main structure in the tropics and midlatitudes. Total ozone was reduced over the tropics, especially the tropical Pacific, but enhanced over the midlatitudes with a pronounced imprint of the planetary wave structure. These main features are also significant in the model simulations, though underestimated in the ensemble mean. A similar tropical ENSO pattern was also found in other analyses of TOMS data and chemical climate models (e.g., Steinbrecht et al., 2006). Over the polar region (where no TOMS data are available) $\mathrm{S} 1$ shows an increase and $\mathrm{S} 2$ a decrease in total ozone, but neither is significant.

We also analysed the zonal mean vertical distribution of ozone in the SOCOL model and compared it to SAGE II data (Fig. 12, left). Prominent features in the observations are high concentrations in the midlatitude lower stratosphere and the subtropical upper stratosphere and low ozone concentrations in the tropical middle stratosphere. Both S1 and S2 also show an ozone decrease in the tropical stratosphere. The midlatitude signal is well reproduced both with respect to altitude and magnitude of the signal. These anomalies are all statistically significant in the ensemble means. However, the ozone increase in the subtropical upper stratosphere is not reproduced.

In order to obtain a better picture of the ozone anomalies at middle and high latitudes we plotted ozone differences as a function of equivalent latitudes (Fig. 12, right). This allows focussing on the effects of chemistry and of the meridional circulation by removing the planetary wave imprint. CATO was used as the corresponding observational data set. The transformation to the equivalent latitude coordinates was only possible for $\mathrm{S} 2$, which, as discussed above, fits worse with the observations in the stratosphere than S1. The most pronounced feature is the ozone increase poleward of $65^{\circ}$ equivalent latitude (which is not reproduced by S2), providing clear evidence for a strong ozone increase in the Arctic lower stratosphere. Outside the Arctic the agreement between S2 and CATO is good. Interestingly, the positive ozone anomaly in the subtropical middle stratosphere found in SAGEII and CATO appears also in S2 after the transformation to equivalent latitude coordinates.

\section{Discussion}

At the Earth's surface, SOCOL reproduced the main anomalies of the two winters 1987 and 1989 relatively well with respect to most analysed features, even though the magnitudes of the anomalies are underestimated. Most importantly, both analysed models reproduced the changes in the circulation over the Pacific-North American and North 

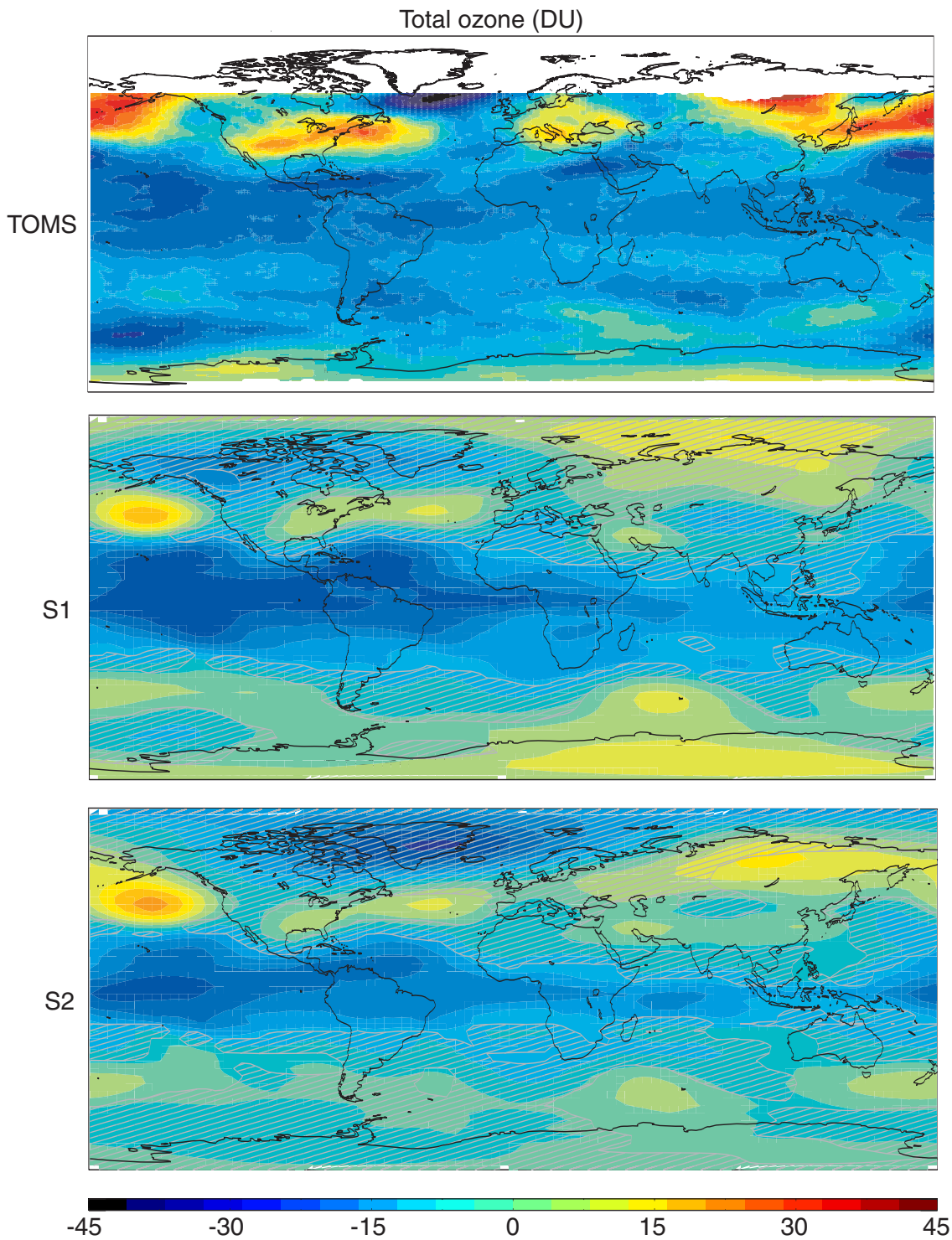

Fig. 11. Difference between 1987 and 1989 in total ozone, averaged from January to March, in TOMS Version 8 data, S1, and S2. Hatched areas are not significantly different from zero ( $t$-test, $p<0.05)$.

Atlantic-European sectors, i.e., a strengthened Aleutian low and weakened Icelandic low, which is important with respect to the stratospheric signal (Brönnimann et al., 2004). The model results are in good agreement with studies performed with other models (e.g., Mathieu et al., 2004). Note that the results do not imply a causal relationship between the extratropical anomalies and ENSO, as SST fields were prescribed globally. For the same reasons, care should be taken when drawing conclusions on predictability (see van Oldenborgh, 2005). What would be necessary to address these issues are sensitivity experiments prescribing only the tropical or only the Indo-Pacific SSTs and setting the remaining SSTs to climatology (or using a mixed-layer ocean), which is beyond the scope of this paper.
However, the model simulations and comparison with observations do allow conclusions with respect to the processes behind ENSO effects on the stratosphere and stratospheretroposphere coupling, given the consistent tropospheric ENSO response. SOCOL reproduced the observed anomalies of lower stratospheric temperature, GPH as well as total ozone in the tropics. This is the typical ENSO pattern that is directly related to the longitudinal shift of the region of intense atmospheric convection (Hatsushika and Yamazaki, 2001). All sets of simulations also reproduced a planetary wave imprint in the midlatitude lower stratosphere that appears in the fields of GPH, total ozone (in SOCOL), and to some extent temperature. Deficiencies have been detected in $\mathrm{S} 1$ and S2 in the representation of the stratospheric wavepattern during the La Niña case. 

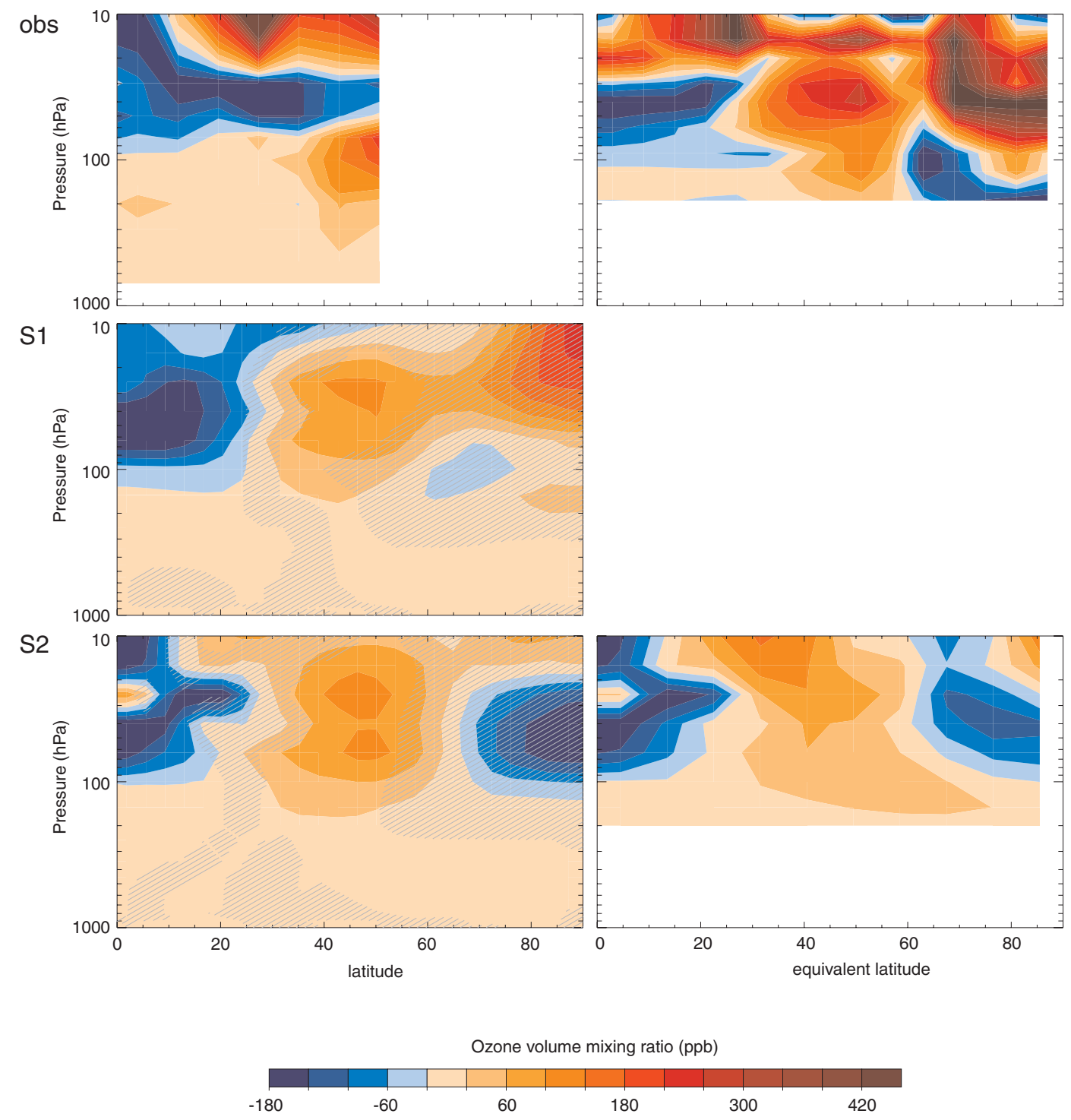

Fig. 12. Difference between 1987 and 1989 in zonal mean ozone mixing ratio as a function of latitude and altitude, averaged from January to March, in observations (SAGE II and CATO), S1, and S2. Left: geographical latidues, right: equivalent latitudes. Hatched areas are not significantly different from zero $(t$-test, $p<0.05)$.

Of special interest with respect to the polar stratosphere are the features that are supposedly caused by wave-mean flow interaction. Brönnimann et al. (2004) suggested that El Niño (relative to La Niña) increases the planetary wave activity propagating from the troposphere to the stratosphere (see also Sassi et al., 2004; Manzini et al., 2006; Garcia-Herrera et al., 2006). Increased upward propagating planetary wave activity, which accompanies the negative NAO mode, is expected to lead to a weak polar vortex, higher temperature of the Arctic stratosphere in spring, and more major midwinter warmings (Taguchi and Hartmann, 2006). At the same time, the meridional circulation is expected to be strengthened, transporting more ozone from the tropical source regions to the extratropics, which would lead to higher ozone column at mid latitudes and especially in the polar vortex, where the descent is enhanced (see Randel et al., 2002). In addition, reduced chemical ozone depletion (because of the warmer temperatures) would further increase the Arctic ozone column (Sassi et al., 2004).

The observations are in very good agreement with this hypothesis. They not only exhibit all of the features discussed above (for El Niño minus La Niña a weak and warm polar vortex, a major midwinter warming, more ozone at mid latitudes and in the polar vortex and less ozone, in the tropics, most pronounced in the CATO data), but also show anomalous EP flux convergence in the stratosphere, which indicates strengthened planetary-wave driving. The analysis of the meridional mass streamfunction provides clear evidence for 
a strengthening of the Brewer-Dobson circulation, especially in the lower-to-middle stratosphere. The SOCOL model reproduces most of the features up to around $30 \mathrm{hPa}$ ( $\mathrm{S} 1$ better than S2) and hence compares reasonably well, at least qualitatively, with the observations and with other modelling studies (see e.g., Sassi et al., 2004; Manzini et al., 2006; GarciaHerrera et al., 2006). However, the signal in the stratosphere, especially in the middle stratosphere and in the polar vortex, is too weak when compared with observations and some of the prominent features in the observations that are supposedly caused by ENSO are not significant in the ensemble mean.

The agreement between S1, S2, and observations is very good for the meridional component and the divergence of the EP flux, somewhat less so for the vertical component. The results imply that the observed and modelled weakening of the polar vortex during El Niño is largely due to wave-mean flow interaction (see also Manzini et al., 2006). It is interesting to note that not only the vertical component of the EP flux (and thus the amount of wave energy that reaches the stratosphere) contributes, but also the meridional component (and thus the degree to which this wave energy is refracted poleward). This is in agreement with the results of Chen et al. (2003) who distinguish between two modes of interannual EP flux variability: a tropospheric mode that is strongly related to the Northern Annular Mode (or NAO) and controls upward propagation of planetary wave energy as well as a stratospheric mode which is strongly related to ENSO and the Pacific North American pattern and controls the poleward refraction of wave energy. The modes are defined as a tropospheric and stratospheric dipole in the anomaly field of EP flux divergence, respectively (see Chen et al., 2003). Both dipoles also appear in the difference field of EP flux divergence in the ERA40 reanalysis and, somewhat less clear, in S1 and S2 (Fig. 9). Thus, in the "canonical" ENSO case, both patterns contribute.

With respect to ozone, all of the above results suggest a strengthening of the Brewer-Dobson circulation, which is particularly evident in the meridional mass streamfunction (Fig. 10). This leads to a decrease of ozone concentrations in the tropical lower stratosphere and an increase at mid latitudes and in the polar lower stratosphere (see also Sassi et al., 2004; Pyle et al., 2005; Garcia-Herrera et al., 2006). The chemical contribution at high latitudes has the same sign as the dynamical contribution, but is dependent on temperature and might therefore be underestimated by SOCOL.

The comparison between $\mathrm{S} 1$ and $\mathrm{S} 2$ shows that both agree well with each other and with observations in the tropics. S1 fits better with the observations in the Arctic stratosphere (but S2 also reproduces some of the features such as the weak polar vortex during El Niño). The differences between $\mathrm{S} 1$ and S2 are consistent among EP flux, zonal wind, streamfunction, and ozone and seem to be related to a weaker wave-driving signal in S2. However, the differences are not statistically significant and can not be attributed to changes in the model set-up, which affect absolute values more than differences between El Niño and La Niña case. Generally, significant differences between El Niño and La Niña in one ensemble set are mostly also significant in the other one. In this sense, comparing S1 and S2 suggests that results are relatively robust with respect to changes in the model set-up.

\section{Conclusions}

The main anomalies in atmospheric circulation and ozone observed during the "canonical" ENSO cycle 1986-1989 were successfully reproduced with the chemical climate model SOCOL. While deficiencies could be identified with respect to the signal in the middle to upper stratosphere and with respect to vertical wave propagation in the La Niña case, the ENSO signal in surface climate, especially the circulation over the North Atlantic-European region, as well as the imprint in the lower stratosphere agree well with observations. Comparison with GCM runs confirmed that the tropospheric response is a robust response to the SST forcing and hence we interpret the stratospheric signal in terms of a coupling to this tropospheric response. As such, the results provide insight into the mechanisms relating ENSO to stratospheric circulation changes. They suggest that both the upward and poleward components of anomalous EP flux are important for obtaining the stratospheric ENSO signal and that an increase in strength of the Brewer-Dobson circulation during El Niño is part of that signal.

Acknowledgements. SB was funded by the Swiss National Science Foundation, AF is funded by ETH Zürich (TH project CASTRO). TE was supported by Swiss National Science Foundation and COST-724. GPCP data were obtained via NOAA/CIRES-CDC. We thank G. Compo and P. Sardeshmukh for providing the MRF9 simulations, NASA for providing TOMS and SAGE II data, and I. Wohltmann for providing data and support for the calculation of EP fluxes. ECMWF ERA-40 data used in this study have been provided by ECMWF.

Edited by: V. Fomichev

\section{References}

Adler, R. F., Huffman, G. J., Chang, A., Ferraro, R., Xie, P., Janowiak, J., Rudolf, B., Schneider, U., Curtis, S., Bolvin, D., Gruber, A., Susskind, J., and Arkin, P.: The Version 2 Global Precipitation Climatology Project (GPCP) monthly precipitation analysis (1979-Present), J. Hydrometeor., 4, 1147-1167, 2003.

Alexander M. A., Bladé, I., Newmann, M., Lanzante, J. R., Lau, N.-C., and Scott, J. D.: The atmospheric bridge: The influence of ENSO teleconnnections on air-sea interaction over the global oceans, J. Clim., 15, 2205-2231, 2002.

Ambaum, M. H. P. and Hoskins, B. J.: The NAO tropospherestratosphere connection, J. Clim., 15, 1969-1978, 2002.

Andrews, D. G., Holton, J. R., Leovy, C. B.: Middle Atmosphere Dynamics, Academic Press, 1987. 
Baldwin, M. P. and Dunkerton, T. J.: Stratospheric harbingers of anomalous weather regimes, Science, 294, 581-584, 2001.

Brönnimann, S., Luterbacher, J., Staehelin, J., Svendby, T. M., Hansen, G., and Svenøe, T.: Extreme climate of the global troposphere and stratosphere 1940-1942 related to El Niño, Nature, 431, 971-974, 2004.

Brunner, D., Staehelin, J., Kuensch, H. R., and Bodeker, G. E.: A Kalman filter reconstruction of the vertical ozone distribution in an equivalent latitude - potential temperature framework from TOMS/GOME/SBUV total ozone observations, J. Geophys. Res., 111, D12308, doi:10.1029/2005JD006279, 2006.

Butchart, N. and Austin, J.: Middle atmosphere climatologies from the troposphere-stratosphere configuration of the UKMO's Unified Model, J. Atmos. Sci., 55, 2782-2809, 1998.

Chen, W., Takahashi, M., and Graf, H.-F.: Interannual variations of planetary wave activity in the northern winter troposphere and stratosphere and their relations to NAM and SST, J. Geophys. Res. 108, 4797, doi:10.1029/2003JD003834, 2003.

Claud, C., Scott., N. A., and Chedin, A.: Seasonal, interannual and zonal temperature variability of the tropical stratosphere based on TOVS satellite data: 1987-1991, J. Clim., 12, 540-550, 1999.

Compo, G. P. and Sardeshmukh, P. D.:Storm Track predictability on seasonal and decadal scales, J. Clim., 17, 3701-3720, 2004.

Compo, G. P., Sardeshmukh, P. D., and Penland, C.: Changes of subseasonal variability associated with El Niño, J. Clim., 14, 3356-3374, 2001.

Egorova, T. A., Rozanov, E. V., Zubov, V. A., and Karol, I. L.: Model for Investigating Ozone Trends (MEZON), Izvestiya, Atmos. Oceanic Phys., 39, 277-292, 2003.

Egorova, T., Rozanov, E., Manzini, E., Haberreiter, M., Schmutz, W., Zubov, V., Peter, T.: Chemical and dynamical response to the 11-year variability of the solar irradiance simulated with a chemistry-climate model, Geophys. Res. Lett., 31, L06119, doi:10.1029/2003GL019294, 2004.

Egorova, T., Rozanov, E., Zubov, V., Manzini, E., Schmutz, W., and Peter, T.: Chemistry-climate model SOCOL: a validation of present-day climatology, Atmos. Chem. Phys., 5, 1577-1576, 2005 ,

http://www.atmos-chem-phys.net/5/1577/2005/.

Eyring, V., Butchart, N., Waugh, D. W., et al.: Assessment of temperature, trace species and ozone in chemistry-climate model simulations of the recent past, J. Geophys. Res., 2006, in press.

Fouquart, Y. and Bonnel, B.: Computations of solar heating of the Earth's atmosphere: A new parameterization, Beitr. Phys. Atmos., 53, 35-62, 1980.

Fraedrich, K.: An ENSO impact on Europe? A review, Tellus, 46A, 541-552, 1994.

Fraedrich, K., and Müller, K.: Climate anomalies in Europe associated with ENSO extremes, Int. J. Climatol., 12, 25-31, 1992.

Garcia-Herrera, R., Calvo, N., Garcia, R. R., and Giorgetta, M. A.: Propagation of ENSO temperature signals into the middle atmosphere: A comparison of two general circulation models and ERA-40 reanalysis data, J. Geophys. Res., 111, D06101, doi:10.1029/2005JD006061, 2006.

Giorgetta, M. A.: Der Einfluss der quasi-zweijaehrigen Oszillation auf die allgemeine Zirkulation: Modellrechnungen mit ECHAM4, Examensarbeit Nr. 40, Universität Hamburg, Hamburg, Germany, 1996.

Gouirand, I. and Moron, V.: Variability of the impact of El Niño- southern oscillation on sea-level pressure anomalies over the North Atlantic in January to March (1874-1996), Int. J. Climatol., 23, 1549-1566, 2003.

Hartmann, D. L., Wallace, J. M., Limpasuvan, V., Thompson, D. W. J., and Holton J. R.: Can ozone depletion and greenhouse warming interact to produce rapid climate change?, Proc. Nat. Acad. Sci., 97, 1412-1417, 2000.

Hatsushika, H. and Yamazaki, K.: Interannual variations of temperature and vertical motion at the tropical tropopause associated with ENSO, Geophys. Res. Lett., 28, 2891-2894, 2001.

Hoerling, M. P. and Ting, M. F.: Organization of extratropical transients during El Niño, J. Clim., 7, 745-766, 1994.

Hoerling, M. P., Blackmon, M. L., and Ting, M.: Simulating the atmospheric response to the 1985-1987 El Niño cycle, J. Clim., 5, 669-682, 1992.

Kistler, R., Kalnay, E., Collins, W., et al.: The NCEP-NCAR 50year reanalysis: Monthly means CD-ROM and documentation, Bull. Am. Meteorol. Soc., 82, 247-267, 2001.

Kousky, V. E. and Leetma, A.: The 1986-87 Pacific warm episode: Evolution of oceanic and atmospheric anomaly fields, J. Clim., 2, 254-267, 1989.

Kumar, A., Hoerling, M. P., Ji, M., Leetma, A., and Sardeshmukh, P.: Assessing a GCM's suitability for making seasonal predictions, J. Clim., 9, 115-129, 1996.

Lean, J.: Evolution of the Sun's spectral irradiance since the maunder minimum, Geophys. Res. Lett., 27, 2425-2428, 2000.

Labitzke, K., Kunze, M., and Brönnimann S.: Sunspots, the QBO and the stratosphere in the North Polar region - 20 years later, Meteorol. Z., 15, 355-363, 2006.

Manzini, E., McFarlane, N. A., and McLandress, C.: Impact of the Doppler Spread Parameterization on the simulation of the middle atmosphere circulation using the MA/ECHAM4 general circulation model, J. Geophys. Res., 102, 25 751-25 762, 1997.

Manzini, E., Giorgetta, M. A., Esch, M., Kornblueh, L., and Roeckner, E.: The influence of sea surface temperatures on the Northern winter stratosphere: Ensemble simulations with the MAECHAM5 model, J. Clim., 19, 3863-3881, 2006.

Mariotti, A., Zeng N., and Lau K.-M.: Euro-Mediterranean rainfall and ENSO_a seasonally varying relationship, Geophys. Res. Lett., 29, 1621, doi:10.1029/2001GL014248, 2002.

Mathieu, P. P., Sutton, R. T., Dong, B. W., and Collins, M.: Predictability of winter climate over the North Atlantic European region during ENSO events, J. Clim., 17, 1953-1974, 2004.

McPhaden, M. J., Hayes, S. P., and Mangum, L. J.: Variability in the Western equatorial Pacific Ocean during the 1986/87 El Niño/Southern Oscillation event, J. Phys. Oceanogr., 20, 190208, 1990.

Melo-Gonçalves, P., Rocha, A. C., Castanheira, J. M., and Ferreira, J. A.: North Atlantic Oscillation sensitivity to the El Niño/Southern Oscillation polarity in a large-ensemble simulation, Clim. Dyn., 24, 599-606, 2005.

Merkel, U. and Latif, M.: A high resolution AGCM study of the El Niño impact on the North Atlantic/European sector, Geophys. Res. Lett., 29, 1291, doi:10.1029/2001GL013726, 2002.

Miller, L., Cheney, R., and Douglas, B. C.: GEOSAT altimeter observations of Kelvin waves and the 1986-87 El Niño, Science, 239, 52-54, 1988.

Morcrette, J. J.: Radiation and cloud radiative properties in the European Center for Medium-Range Weather Forecasts forecasting 
system, J. Geophys. Res., 96, 9121-9132, 1991.

Moron, M. and Plaut, G.: The impact of El Niño Southern Oscillation upon weather regimes over Europe and the North Atlantic boreal winter, Int. J. Climatol., 23, 363-379, 2003.

Palmer, T. N. and Anderson D. L. T.: Scientific assessment of the prospect of seasonal forecasting: a European perspective, ECMWF Technical report, 70, 1993.

Pyle, J. A., Braesicke, P., and Zeng, G.: Dynamical variability in the modelling of chemistry-climate interactions, Faraday Discuss., 130, 27-39, 2005.

Pozo-Vázquez, D., Gámiz-Fortis, S. R., Tovar-Pescador, J., Esteban-Parra, M. J., and Castro-Díez, Y.: North Atlantic winter SLP anomalies based on the autumn ENSO state, J. Clim., 18, 97-103, 2005.

Randel, W. J., Wu, F., and Stolarski R.: Changes in column ozone correlated with the stratospheric EP flux, J. Meteorol. Soc. Jpn., 80, 849-862, 2002.

Rozanov, E. V., Schlesinger, M. E., Zubov, V. A., Yang, F., and Andronova, N. G.: The UIUC three-dimensional stratospheric chemical transport model: Description and evaluation of the simulated source gases and ozone, J. Geophys. Res., 104, $11755-$ $11781,1999$.

Rozanov, E., Schraner, M., Schnadt, C., Egorova, T., Wild, M., Ohmura, A., Zubov, V., Schmutz, W., and Peter, T.: Assessment of the ozone and temperature variability during 1979-1993 with the chemistry-climate model SOCOL, Adv. Space Res., 35, 1375-1384, 2005.

Sardeshmukh, P. D., Compo, G. P., and C. Penland, C.: Changes of probability associated with El Niño, J. Clim., 13, 4268-4286, 2000.
Sassi, F., Kinnison, D., Boville, B. A., Garcia, R. R., and Roble, R.: Effect of El Niño-Southern Oscillation on the dynamical, thermal, and chemical structure of the middle atmosphere, J. Geophys. Res., 109, D17108, doi:10.1029/2003JD004434, 2004.

Sato, M., Hansen, J., McCormick, M. P., and Pollack, J. B.: Stratospheric aerosol optical depths, 1850-1990, J. Geophys. Res., 98, 22 987-22 994, 1993.

Steinbrecht, W., Hassler, B., Brühl, C., Dameris, M., Giorgetta, M. A., Grewe, V., Manzini, E., Matthes, S., Schnadt, C., Steil, B., and Winkler, P.: Interannual variation patterns of total ozone and temperature in observations and model simulations, Atmos. Chem. Phys., 6, 349-374, 2006, http://www.atmos-chem-phys.net/6/349/2006/.

Taguchi, M. and Hartmann, D. L.: Increased occurrence of stratospheric sudden warmings during El Niño as simulated by WACCM, J. Clim., 19, 324-332, 2006.

Thomason, L. W. and Peter T.: The Assessment of Stratospheric Aerosol Properties, SPARC Newsletter, 26, 38-39, 2006.

van Loon, H. and Labitzke, K.: The Southern Oscillation. Part V: The anomalies in the lower stratosphere of the Northern Hemisphere in winter and a comparison with the Quasi-Biennial Oscillation, Mon. Wea. Rev., 115, 357-369, 1987.

van Oldenborgh, G. J.: Comment on "Predictability of winter climate over the North Atlantic European region during ENSO events" by P.-P. Mathieu, R. T. Sutton, B. Dong and M. Collins, J. Clim., 18, 2770-2772, 2005.

Uppala, S. M., Kållberg, P. W., Simmons, A. J., et al.: The ERA40 re-analysis, Q. J. R. Meteorol. Soc., 131, 2961-3012, 2005.

Wu, A. and Hsieh, W. W.: The nonlinear association between ENSO and the Euro-Atlantic winter sea level pressure, Clim. Dyn., 23, 859-868, 2004. 